DOI: https://doi.org/10.47405/mjssh.v7i1.1243

\begin{tabular}{|c|c|}
\hline isis & Malaysian Journal of Social Sciences and Humanities (MJSSH) \\
\hline $\begin{array}{l}\text { Malaysian Journal of } \\
\text { Soly }\end{array}$ & Volume 7, Issue 1, January 2022 \\
\hline (MJ-sSH) & e-ISSN : 2504-8562 \\
\hline & $\begin{array}{l}\text { Journal home page: } \\
\text { www.msocialsciences.com }\end{array}$ \\
\hline
\end{tabular}

\title{
Minda Usahawan antara Pelajar Lelaki dan Perempuan Pra-Universiti
}

\author{
Rohana Rahim ${ }^{1}$, Norasmah Othman' \\ 1Fakulti Pendidikan, Universiti Kebangsaan Malaysia (UKM), Malaysia \\ Correspondence: Rohana Binti Rahim (annarahim1981@gmail.com)
}

\begin{abstract}
Abstrak
Kajian tinjauan ini bertujuan untuk mengenal pasti tahap minda usahawan antara pelajar lelaki dan perempuan pra-universiti di negeri Johor. Seramai 320 orang pelajar pra-universiti telah dipilih secara rawak sebagai responden kajian ini. Instrumen soal selidik digunakan bagi mendapatkan data daripada responden. Data dianalisis dengan menggunakan kaedah statistik deskriptif yang melibatkan skor min dan sisihan piawai. Ujian inferensi digunakan bagi menganalisis perbezaan minda usahawan antara pelajar lelaki dan perempuan pra-universiti. Perisian Statistical Package Social Science (SPSS) versi 25 digunakan dalam kajian ini untuk menganalisis data. Hasil kajian ini mendapati minda usahawan pelajar lelaki dan perempuan pra-universiti berada pada tahap sederhana. Namun, tidak terdapat perbezaan yang signifikan terhadap tahap minda usahawan antara pelajar lelaki dan perempuan prauniversiti. Implikasi kajian ini adalah mencadangkan agar pelajar didedahkan lebih luas lagi berkaitan pengetahuan dan pengalaman keusahawanan agar dapat meningkatkan tahap minda usahawan pelajar.
\end{abstract}

Kata kunci: minda usahawan, pelajar lelaki pra-universiti, pelajar perempuan pra-universiti

\section{The Entrepreneurial Mindset Among Male and Female Pre-University Students}

\begin{abstract}
This survey study aims to identify the level of entrepreneurial mindset among male and female preuniversity students in Johor. A total of 320 pre-university students were randomly selected as respondents of this study. Questionnaire instruments were used to obtain data from respondents. Data were analyzed using descriptive statistical methods involving mean scores and standard deviations. Inference tests were used to analyze the differences in entrepreneurial mindset between male and female pre-university students. Statistical Package for Social Science (SPSS) version 25 software was used in the study to analyze data. The results of this study found that the entrepreneurial mindset of male and female pre-university students are at a moderate level. However, there was no significant difference in the level of entrepreneurial mindset between male and female pre-university students. The implications of this study is to suggest that students be exposed more widely related to entrepreneurial knowledge and experience in order to increase the level of entrepreneurial mindset of students.
\end{abstract}

Keywords: entrepreneurial mindset, male pre-university students, female pre-university students 


\section{Pengenalan}

Pendidikan merupakan suatu proses menuntut ilmu dalam kehidupan manusia serta menjadi agenda utama yang boleh meningkatkan ketamadunan sesebuah bangsa di seluruh dunia (Hussin et al., 2010). Menurut Amie dan Mohd Jasmy (2019), pendidikan juga memainkan peranan penting dalam melahirkan modal insan yang mempunyai jati diri yang kukuh, berketerampilan, berkeperibadian mulia, berpengetahuan dan berkemahiran tinggi. Malah pendidikan dikatakan sebagai hak asasi manusia dan berfungsi dalam pembangunan manusia, sosial dan ekonomi (Global Partnership for Education, 2020). Dengan adanya pendidikan, seseorang akan mendapat lebih banyak peluang dalam kehidupan dan seterusnya ketidaksamarataan jantina dapat dielakkan.

Singapura merupakan antara negara yang mempunyai sistem pendidikan terbaik di dunia di mana berada di tempat keempat dunia dan yang pertama di Asia (Laporan Daya Saing Global, 2020). Malaysia juga telah diiktiraf memiliki kualiti pendidikan kedua terbaik selepas Singapura di peringkat Asia (World Economic Forum, 2018). Hal ini menunjukkan bahawa Malaysia adalah antara negara yang mempunyai daya saing yang kompetitif dan progresif. Seterusnya berupaya melahirkan pelajar berminda usahawan yang mempunyai kemahiran membuat keputusan, kemahiran menyelesaikan masalah, kemahiran mengesan peluang, berani mengambil risiko, kreativiti dan inovasi serta kemahiran bekerja dalam pasukan. Bukan itu sahaja, pendidikan di Malaysia telah berjaya merapatkan jurang gender selain daripada bidang kesihatan (Indeks Jurang Gender Global, 2021).

Kementerian Pendidikan Malaysia (KPM) bertanggungjawab menguruskan sistem pendidikan negara di peringkat sekolah yang meliputi prasekolah, pendidikan rendah, pendidikan menengah dan pendidikan lepasan menengah. Pendidikan lepasan menengah ini terdiri daripada pendidikan prauniversiti dan juga pendidikan matrikulasi. Pendidikan pra-universiti merupakan suatu medium yang memberi peluang kepada pelajar lepasan Sijil Pelajaran Malaysia melanjutkan pelajaran. Pendidikan pada peringkat pra-universiti adalah landasan bagi pelajar untuk menyambung pengajian ke peringkat menara gading (Poh \& Melissa, 2008). Pelajar akan menjalani pengajian pra-univeristi selama setahun setengah dan menduduki peperiksaan Sijil Tinggi Persekolahan Malaysia. Pelan Pembangunan Pendidikan Malaysia (PPPM) 2013-2015 telah menggariskan setiap pelajar perlu mempunyai enam aspirasi dan salah satunya adalah kemahiran berfikir. Pelajar juga perlu menguasai pelbagai kemahiran berfikir termasuk penyelesaian masalah, penaakulan, dan pemikiran kreatif dan inovatif (KPM, 2020). Pelajar pra-universiti merupakan bakal pemimpin pada masa hadapan dan perlu diasah kemahiran dalam diri mereka agar dapat membentuk individu yang kreatif, inovatif serta mempunyai pemikiran aras tinggi. Hal ini menunjukkan hasrat KPM untuk melahirkan pelajar yang mempunyai minda usahawan. Menurut Armanurah et al. (2015) pelajar yang mempunyai minda keusahawanan berupaya berfikir pada tahap yang tinggi dan kompleks.

Kemodenan dan kepantasan perkembangan teknologi maklumat masa kini yang hanya dihujung jari memberikan pelbagai cabaran baru dan tekanan kepada pelajar. Ketika ini, pelajar dikehendaki berupaya membuat keputusan yang tepat, menyelesaikan masalah, berani mengambil risiko serta berdaya saing. Tekanan menjadi lebih serius apabila mereka juga perlu berkemampuan untuk meneroka peluang pekerjaan selepas bergraduasi. Sekiranya pelajar lemah dalam membuat keputusan, menyelesaikan masalah, mengesan peluang dan tidak berani mengambil risiko, mereka akan berdepan dengan risiko seperti peluang mendapat pekerjaan. Selain menyumbang kepada isu pengangguran, kelemahan dalam penguasaan kemahiran tersebut mengakibatkan kepuasan dalam bekerja tidak dapat dikecapi (Zafir et al., 2015; Rahmah et al., 2011). Laporan yang dikeluarkan oleh Jabatan Perangkaan Malaysia menunjukkan kadar pengangguran dalam kalangan belia yang berusia dari umur 15 sehingga 24 tahun meningkat sebanyak $0.4 \%$ kepada $13.9 \%$ pada bulan Februari 2021 berbanding dengan Januari 2021.

Terkini dilaporkan terdapat sebilangan besar graduan pra-universiti tidak mempunyai pengetahuan dan kemahiran yang dikehendaki majikan seperti kemahiran berkomunikasi, kemahiran menetapkan keputusan serta kompetensi dalam berbahasa inggeris (Muhammad Hazrul, 2012). Hal ini memberi kesan kepada kebolehpasaran dan kebolehgajian graduan pra-universiti. Berikutan kepada kajian yang dilakukan oleh Hazilah et al. (2013), mereka mendapati pihak majikan sama ada sektor awam ataupun 
swasta memberi keutamaan kepada graduan yang memiliki kemahiran insaniah bagi jawatan yang ditawarkan. Walaupun graduan pra-universiti merancang untuk terus bekerja atau menyambung pengajian ke peringkat yang lebih tinggi, graduan perlu menyiapkan diri dengan penguasaan kemahiran berfikir secara kreatif dan kritis dengan menggunakan tekonologi bagi menyelesaikan masalah, bekerjasama, berkomunikasi dengan baik serta mendapatkan informasi dengan pantas dan berkesan (Maimunah \& Hashimah, 2017). Hal ini menunjukkan pelajar pra-universiti perlu mempunyai elemenelemen minda usahawan bagi mencapai kehendak majikan.

Indeks Jurang Gender Global 2021 melaporkan kedudukan Malaysia berada di tangga yang ke-112 daripada 156 negara. Namun, kedudukan negara jiran seperti Filipina, Singapura, Indonesia dan juga Brunei lebih terkehadapan. Ini menunjukkan bahawa Malaysia mempunyai jurang gender yang sangat luas berbanding dengan negara anggota Asia Tenggara yang lain. Jurang antara wanita dan lelaki ini dilihat dari segi penglibatan dalam sektor ekonomi, pendidikan, kesihatan dan juga politik (Siti Fatimah, 2020). Berdasarkan laporan Statista menunjukkan seramai 291,530 pelajar lelaki yang mendaftar di Universiti Awam pada tahun 2019. Manakala jumlah pelajar perempuan yang mendaftar pada tahun yang sama iaitu seramai 415,020 orang. Jurang pencapaian antara gender yang berlaku di sekolah menyebabkan perbezaan enrolmen pelajar perempuan dan lelaki di peringkat yang lebih tinggi (Hanita \& Norzaini, 2018). Namun, statistik pelibatan wanita dalam bidang ekonomi agak rendah dan tidak tinggi seperti statistik pelajar perempuan mendaftar di universiti. Kadar penyertaan tenaga buruh juga melaporkan peratus tenaga buruh lelaki jauh lebih tinggi berbanding dengan tenaga buruh wanita. Ini menunjukkan bahawa kadar kebolehpasaran tenaga buruh lelaki adalah tinggi. Kadar kebolehpasaran graduan lelaki yang tinggi adalah disebabkan mereka lebih menguasai kemahiran insaniah atau minda usahawan berbanding graduan perempuan (Sharifah \& Haslinawati, 2018). Perkara ini menjadi tanda tanya kepada pelbagai pihak, kenapa senario seumpama berlaku. Oleh itu, satu kajian dijalankan yang bermatlamat untuk:

i. Mengenal pasti tahap minda usahawan pelajar lelaki dan perempuan pra-universiti

ii. Mengenal pasti perbezaan tahap minda usahawan pelajar lelaki dan perempuan pra-universiti

\section{Sorotan Literatur}

\section{Minda Usahawan}

Minda boleh didefinisikan sebagai keupayaan kognitif untuk berfikir, menaakul, membuat keputusan serta pertimbangan. Minda usahawan adalah kemahiran berfikir dan membuat keputusan yang dapat dilaksanakan dalam situasi yang rumit, tidak menentu dan dinamik (Naumann, 2017). Minda usahawan juga boleh ditakrifkan sebagai tingkah laku seseorang yang cenderung kepada penerokaan, penilaian dan penggunaan peluang terhadap aktiviti dan hasil keusahawanan (Bosman \& Fernhaber, 2018).

Set minda keusahawanan juga dikenali sebagai mengenal pasti peluang, kecenderungan mengambil risiko, toleransi kekaburan dan kepercayaan diri. Set ini dilaporkan mempunyai perkaitan terus dengan pendidikan keusahawanan (Aida \& Sheerad, 2020). Aida dan Sheerad (2020) mendapati pendidikan keusahawanan dapat menggalakkan perkembangan tingkah laku serta set minda keusahawanan pelajar dalam usaha kerajaan melahirkan lebih ramai lagi usahawan dari kalangan graduan, menurunkan kadar pengangguran dan meningkatkan peluang perniagaan. Untuk itu, Vasanthadevi dan Norasmah (2016) menyatakan guru perlu mempamerkan sikap proaktif di dalam kelas bagi memastikan pelajarnya mempunyai ciri dan minda keusahawanan. Ini sejajar dengan matlamat pendidikan iaitu membudayakan minda keusahawanan dalam kalangan pelajar. Kajian ini mengkaji minda usahawan yang terdiri daripada elemen kemahiran membuat keputusan, kemahiran menyelesaikan masalah, kemahiran mengesan peluang, berani mengambil risiko, kreativiti dan inovasi serta kemahiran bekerja dalam pasukan.

Elemen pertama dalam minda usahawan iaitu kemahiran membuat keputusan. Zakri dan Saemah (2015) mentafsirkan membuat keputusan adalah suatu kemahiran kognitif yang memerlukan pemikiran kritis yang digunakan dalam apa jua keadaan dalam kehidupan seharian. Kemahiran membuat keputusan juga merupakan unsur penting dalam menghasilkan generasi masa depan yang boleh 
membuat keputusan tepat untuk memacu negara (Mazli \& Saemah, 2017). Bagi Safiah et al. (2016) pula, pembuatan keputusan merujuk kepada proses memilih ke atas pilihan alternatif yang ada. Kajian Nor Hamizah et al. (2020) juga mendapati kemahiran membuat keputusan mempunyai hubungan dengan daya tahan yang boleh membantu pelajar untuk mengatasi masalah sosial dan emosi yang dihadapi. Pelajar dikatakan sering membuat keputusan kerana ia sebahagian daripada proses penting dalam kehidupan mereka (Muhammad Hanif et al., 2019). Dalam kajian Safiah et al. (2016) belia yang melibatkan diri dalam proses pembuatan keputusan dapat menghasilkan kemahiran kepimpinan dalam diri belia tersebut. Ciri-ciri seperti pergaulan, keyakinan, kematangan dan sikap terhadap risiko boleh mempengaruhi cara seseorang membuat keputusan (Greenbank, 2010).

Elemen minda usahawan yang seterusnya adalah kemahiran menyelesaikan masalah. Kemahiran menyelesaikan masalah merupakan proses kognitif yang mengenal pasti situasi tertentu untuk memperbaiki dan memperoleh penyelesaian yang sesuai melalui pelbagai kaedah (Normala \& Mohd Azhar, 2019). Azizi (2010) mendefinisikan kemahiran menyelesaikan masalah adalah proses kognitif yang menggunakan maklumat sebagai usaha mencari metod yang sesuai untuk mendapatkan matlamat. Menurut Ayu dan Ariyadi (2018) kemahiran menyelesaikan masalah yang dimiliki oleh pelajar dapat dijadikan sebagai penilaian pembelajaran. Namun, pengalaman menyelesaikan masalah dalam kehidupan seharian biasanya tidak tersusun, kompleks dan pelbagai rupa menyebabkan pelajar tidak berupaya untuk menyelesaikan masalah di luar bilik darjah kerana tidak mempunyai penyelesaian masalah yang sesuai dan peluang aplikasi pengetahuan dalam konteks kehidupan sebenar (Kuang-Chao Yu et al., 2014).

Kemahiran mengesan peluang adalah elemen yang ketiga dalam minda usahawan. Menurut Nor Liza et al. (2019) mengesan peluang adalah mengenal pasti produk atau servis yang mempunyai nilai dan boleh ditukarkan menjadi keuntungan. Kemahiran mengesan peluang bukan sekadar mengenal pasti idea dari peluang yang mempunyai potensi malah dapat mengarahkan seseorang menukarkan peluang menjadi usaha yang berjaya (Wasdani, 2015). Cristian et al. (2011) menyatakan pendidikan keusahawanan akan memberi impak yang besar kepada pelajar dengan melihat dan bertindak mengikut realiti apabila mengenal pasti peluang. Terdapat persamaan antara model proses, kognisi dan metod untuk meningkatkan kreativiti dan kaedah untuk memupuk kecekapan bagi mengesan peluang (Jan, 2015). Marwan dan Yusoff (2014) mengatakan kemahiran mengesan peluang itu adalah kebolehan seseorang melihat sesuatu permasalahan yang berlaku dalam masyarakat adalah satu peluang.

Berani mengambil risiko ditakrifkan sebagai sikap seseorang dalam membuat keputusan untuk menerima dan mengelak risiko pada situasi yang berpotensi mendapat keuntungan dan rugi yang sama banyak (Jauharatul, 2019). Abdul Aziz et al. (2011) mengatakan meskipun usahawan mempunyai sifat berani mengambil risiko, namun perlu membuat pertimbangan yang teliti terlebih dahulu bagi menghadapi risiko. Mohamad Ayub dan Radin Siti (2019) juga bersetuju dengan kenyataan bahawa berani mengambil risiko merupakan ciri keusahawanan yang perlu ada pada seorang usahawan tetapi bukanlah berani secara membuta tuli. Bagi Nahid et al. (2019) pula, individu yang kurang bersedia untuk mengambil risiko sering digambarkan sebagai mengelak risiko dan individu yang lebih bersedia untuk mengambil risiko sering disifatkan sebagai mencari risiko.

Kreativiti merupakan bahagian yang sangat penting dalam proses inovasi (Taylor, 2018). Tambah Taylor lagi, inovasi dikatakan sebagai kreativiti yang menambah kepada proses pengembangan atau penambahbaikan idea, perkhidmatan atau produk baharu. Pelan Pembangunan Pendidikan Malaysia 2013-2025 menekankan bahawa setiap murid perlu menguasai kemahiran kognitif termasuklah kreatif, inovatif, penaakulan dan pemikiran kritis (KPM, 2020). Norfarahi et al. (2020) merumuskan dalam kajiannya dengan menyatakan kreativiti pelajar politeknik didorong oleh ilmu pengetahuan, personaliti, motivasi dan gaya berfikir. Kajian Nor Azzatunnisak (2015) juga mendapati motivasi berperanan bagi meningkatkan penguasaan kemahiran kreatif dan inovasi. Kewujudan persekitaran yang selesa dalam sesebuah organisasi dan memenuhi keperluan dapat mewujudkan budaya kreativiti dan inovasi (Razli et al., 2016).

Elemen terakhir yang terdapat dalam minda usahawan adalah kemahiran bekerja dalam pasukan. Kemahiran bekerja dalam pasukan didefinisikan sebagai sekumpulan manusia yang bekerja secara 
kolektif dan bebas untuk mencapai matlamat serta mempunyai kuasa untuk mengawal sekurangkurangnya sebahagian operasi dan berkomunikasi secara terbuka dan berkesan (Mashitah et al., 2017). Kemahiran bekerja dalam pasukan juga dikatakan keupayaan seseorang untuk berkolaborasi dengan orang lain yang mempunyai latar belakang sosiobudaya yang berbeza untuk mencapai matlamat yang sama (Siti Halijah \& Mohd Faizal, 2018). Setiap ahli pasukan perlu menyumbangkan idea agar keputusan yang dibuat adalah efektif (Muhamad Fairuzzairi et al., 2014). Dapatan kajian Norazila et al. (2017) menunjukkan penglibatan pelajar dalam unit kokurikulum mempunyai perkaitan dengan pembentukan kemahiran bekerja berpasukan pelajar. Akindele (2012) mengatakan aktiviti kerja berpasukan yang sering diadakan di dalam kelas membantu pelajar untuk membuat persiapan diri berinteraksi dengan orang lain di alam pekerjaan kelak.

\section{Pelajar Pra-Universiti}

Menurut Maizan (2017) pelajar pra-universiti merupakan pelajar lepasan menengah yang belajar di tingkatan enam, asasi dan diploma sebelum memasuki universiti bagi menyambung pengajian di peringkat ijazah. Pelajar pra-universiti adalah pelajar yang mempunyai lingkungan umur 18 hingga 19 tahun yang melanjutkan pelajaran di peringkat Sijil Tinggi Pelajaran Malaysia (Siti Zamrah, 2015).

Kajian Abdul Talib et al. (2012) menunjukkan terdapat perbezaan antara pelajar lelaki dan perempuan pra-universiti terhadap aspek aspirasi untuk belajar dan persediaan untuk belajar. Tambahnya lagi, pelajar perempuan dilihat mempunyai keinginan yang tinggi untuk berjaya dalam akademik jika dibandingkan dengan pelajar lelaki. Azizi et al. (2012) mendapati wujud perbezaan perubahan konsep kendiri antara jantina pelajar pra-universiti dalam kajiannya. Justeru, kajian ini ingin mengkaji minda usahawan pelajar lelaki dan perempuan pra-universiti.

\section{Metod Kajian}

Kajian ini memilih pendekatan kuantitatif dengan mengaplikasikan kaedah tinjauan sebagai reka bentuk kajian. Menurut Cresswell (2005) kaedah tinjauan merupakan kaedah yang mengumpul dan menganalisis data pada masa yang sama menyebabkan ia sering diguna pakai dalam penyelidikan pendidikan. Populasi pelajar pra-universiti dalam kajian ini adalah seramai 751 orang. Sampel seramai 254 orang dipilih berdasarkan penentuan saiz sampel Krejcie dan Morgan. Namun, penyelidik menambah saiz sampel sebanyak 66 orang menjadikan sampel seramai 320 orang yang terdiri daripada pelajar pra-universiti untuk mendapatkan keputusan yang lebih baik. Ini berikutan penyataan Cresswell (2014) iaitu saiz persampelan yang lebih besar dapat mengurangkan ralat persampelan.

Borang soal selidik digunakan sebagai instrumen kajian bagi mendapatkan maklumat berkaitan elemen-elemen minda usahawan daripada responden kajian. Data yang dikumpulkan melalui soal selidik ini akan dianalisis secara deskriptif dan inferensi. Instrumen Minda Usahawan Pelajar PraUniversiti digunakan dalam kajian ini diadaptasi dari kajian Norasmah dan Amal (2021). Soal selidik ini mengandungi tujuh bahagian, iaitu bahagian A, B, C, D, E, F dan G. Bahagian A adalah soalan yang merangkumi demografi responden. Seterusnya, bahagian B sehingga bahagian G berkaitan dengan elemen-elemen minda usahawan iaitu kemahiran membuat keputusan, kemahiran menyelesaikan masalah, kemahiran mengesan peluang, keberanian mengambil risiko, kreativiti dan inovasi serta kemahiran bekerja dalam pasukan.

Kajian rintis telah dijalankan terhadap 43 responden untuk meyakinkan instrumen soal selidik boleh diguna pakai. Hasil ujian Cronbach Alpha dan nilai kesahan bagi setiap item kontsruk ditunjukkan di dalam Jadual 1. Item bagi kreativiti dan inovasi menunjukkan nilai Cronbach Alpha yang paling tinggi iaitu 0.907 dengan nilai kesahan 0.809. Nilai keseluruhan Cronbach Alpha bagi instrumen soal selidik ini ialah 0.955. Merujuk kepada Bond et al. (2005) nilai Cronbach Alpha yang menunjukkan nilai 0.8 dan ke atas, ia bermaksud instrumen sangat baik dan boleh diterima. 
DOI: https://doi.org/10.47405/mjssh.v7i1.1243

Jadual 1: Nilai Kesahan dan Kebolehpercayaan

\begin{tabular}{lll}
\hline Item & Nilai Cronbach Alpha & Nilai Kesahan \\
\hline Kemahiran membuat keputusan & 0.837 & 0.760 \\
Kemahiran menyelesaikan masalah & 0.738 & 0.699 \\
Kemahiran mengesan peluang & 0.794 & 0.718 \\
Keberanian mengambil risiko & 0.876 & 0.740 \\
Kreativiti dan inovasi & 0.907 & 0.809 \\
Kemahiran bekerja dalam pasukan & 0.900 & 0.813 \\
\hline
\end{tabular}

(Tahap: Sangat baik dan efektif $=0.8-1.0$, Baik dan boleh diterima $=0.7-0.8$, Boleh diterima $=0.6-0.7$, Item perlu dibaiki $=<0.6$, Item perlu digugurkan $=<0.5$ )

Perisian Statitistical Package For Social Science 25.0 (SPSS) digunakan dalam kajian ini untuk menganalisis data. Semua data dianalisis menggunakan kaedah statistik deskriptif dan inferensi yang menumpukan kepada ujian-t tidak bersandar yang melaporkan frekuensi, peratusan, min, sisihan piawai dan taburan skor. Jadual 2 menunjukkan nilai skor min bagi menentukan tahap responden berdasarkan skala Likert empat mata yang diadaptasi daripada Riduwan (2012).

Jadual 2: Interprestasi Skor Min

\begin{tabular}{ll}
\hline Skor & Tahap \\
\hline $1.00-1.50$ & Kurang Kaitan \\
$1.51-2.50$ & Rendah \\
$2.51-3.50$ & Sederhana \\
$3.51-4.00$ & Tinggi \\
\hline
\end{tabular}

\section{Hasil Kajian}

\section{Tahap Minda Usahawan Pelajar Lelaki dan Perempuan Pra-Universiti}

Hasil analisis deskriptif yang dijalankan mendapati secara keseluruhannya tahap minda usahawan dalam kalangan pelajar lelaki dan perempuan pra-universiti adalah sederhana dengan nilai skor min = 3.16 (s.p = .367). Ini jelas terbukti pada setiap elemen minda usahawan iaitu kemahiran membuat keputusan, kemahiran menyelesaikan masalah, kemahiran mengesan peluang, berani mengambil risiko, kreativiti dan inovasi serta kemahiran bekerja dalam pasukan berada pada tahap sederhana. Merujuk kepada Jadual 3 menunjukkan kemahiran bekerja dalam pasukan mencatat skor min yang paling tinggi iaitu 3.24 dan nilai sisihan piawainya .458 .

Jadual 3: Tahap Minda Usahawan

\begin{tabular}{lll} 
& Min & SP \\
\hline Kemahiran membuat keputusan & 3.16 & .440 \\
Kemahiran menyelesaikan masalah & 3.12 & .424 \\
Kemahiran mengesan peluang & 3.14 & .460 \\
Keberanian mengambil risiko & 3.15 & .458 \\
Kreativiti dan inovasi & 3.13 & .447 \\
Kemahiran bekerja dalam pasukan & 3.24 & .458 \\
\hline Keseluruhan & $\mathbf{3 . 1 6}$ & $\mathbf{. 3 6 7}$ \\
\hline
\end{tabular}

Kemahiran bekerja dalam pasukan merupakan konstruk minda usahawan yang mencatat min tertinggi berbanding dengan konstruk yang lain. Berdasarkan Jadual 4, item G7 (Saya percaya bahawa setiap ahli kumpulan memainkan peranan penting) menunjukkan frekuensi yang tertinggi dengan peratusan 97.5\% (312 orang). Terdapat 54 orang pelajar tidak bersetuju dengan item G4 (Saya boleh berkomunikasi dengan baik untuk membina jaringan sosial dengan ramai orang) dengan peratusan 16.9\%. Tetapi item G9 (Saya sedia bekerjasama dengan ahli kumpulan yang lain) menunjukkan pelajar 
DOI: https://doi.org/10.47405/mjssh.v7i1.1243

bersetuju dengan peratusan yang tinggi iaitu sebanyak 96.6\% (309 orang). Walaupun terdapat pelajar yang tidak boleh berkomunikasi dengan baik untuk membina jaringan sosial, namun mereka tergolong dalam kumpulan pelajar yang bersedia bekerjasama dengan ahli kumpulan yang lain. Ini menunjukkan pelajar pra-universiti amat menggemari aktiviti yang dilaksanakan secara berkumpulan.

Jadual 4: Kemahiran Bekerja Dalam Pasukan

\begin{tabular}{|c|c|c|c|c|c|c|c|c|c|}
\hline \multirow{2}{*}{ Item } & \multirow{2}{*}{ Penyataan } & \multirow{2}{*}{$\begin{array}{l}\text { STS } \\
\text { No. }\end{array}$} & \multicolumn{3}{|c|}{ TS } & \multirow{2}{*}{$\begin{array}{l}\text { S } \\
\text { No. }\end{array}$} & \multicolumn{3}{|c|}{ SS } \\
\hline & & & $\%$ & No. & $\%$ & & $\%$ & No. & $\%$ \\
\hline G1 & $\begin{array}{l}\text { Saya lebih komited jika bekerja } \\
\text { dalam kumpulan. }\end{array}$ & 2 & 0.6 & 48 & 15.0 & 175 & 54.7 & 95 & 29.7 \\
\hline G2 & $\begin{array}{l}\text { Saya menyumbang tenaga untuk } \\
\text { memastikan kecemerlangan } \\
\text { kumpulan. }\end{array}$ & 1 & 0.3 & 13 & 4.1 & 202 & 63.1 & 104 & 32.5 \\
\hline G3 & $\begin{array}{l}\text { Saya memberi idea membina dalam } \\
\text { kumpulan }\end{array}$ & 2 & 0.6 & 29 & 9.1 & 200 & 62.5 & 89 & 27.8 \\
\hline G4 & $\begin{array}{l}\text { Saya boleh berkomunikasi dengan } \\
\text { baik untuk membina jaringan sosial } \\
\text { dengan ramai orang. }\end{array}$ & 1 & 0.3 & 53 & 16.6 & 179 & 55.9 & 87 & 27.2 \\
\hline G5 & $\begin{array}{l}\text { Saya membantu rakan sekumpulan } \\
\text { dalam menyelesaikan masalah }\end{array}$ & 1 & 0.3 & 15 & 4.7 & 192 & 60.0 & 112 & 35.0 \\
\hline G6 & $\begin{array}{l}\text { Saya bertindak sebagai pendamai } \\
\text { jika berlaku konflik dalam } \\
\text { kumpulan. }\end{array}$ & 6 & 1.9 & 46 & 14.4 & 202 & 63.1 & 66 & 20.6 \\
\hline G7 & $\begin{array}{l}\text { Saya percaya bahawa setiap ahli } \\
\text { kumpulan memainkan peranan } \\
\text { penting. }\end{array}$ & 4 & 1.3 & 4 & 1.3 & 176 & 55.0 & 136 & 42.5 \\
\hline G8 & $\begin{array}{l}\text { Saya memastikan setiap ahli } \\
\text { kumpulan faham dengan jelas } \\
\text { tugasan masing-masing. }\end{array}$ & 3 & 0.9 & 14 & 4.4 & 192 & 60.0 & 111 & 34.7 \\
\hline G9 & $\begin{array}{l}\text { Saya sedia bekerjasama dengan } \\
\text { ahli kumpulan yang lain. }\end{array}$ & 1 & 0.3 & 10 & 3.1 & 181 & 56.6 & 128 & 40.0 \\
\hline G10 & $\begin{array}{l}\text { Saya membina hubungan harmoni } \\
\text { dalam kumpulan. }\end{array}$ & 1 & 0.3 & 15 & 4.7 & 180 & 56.3 & 124 & 38.8 \\
\hline G11 & $\begin{array}{l}\text { Saya meraikan perbezaan } \\
\text { pandangan sesama ahli. }\end{array}$ & 6 & 1.9 & 18 & 5.6 & 186 & 58.1 & 110 & 34.4 \\
\hline & Skor Min & 3.24 & & & & & & & \\
\hline & Sisihan Piawai & .458 & & & & & & & \\
\hline
\end{tabular}

Seterusnya, elemen kemahiran membuat keputusan berada pada tempat kedua dengan mencatat skor min 3.16 beserta sisihan piawainya .440. Berdasarkan Jadual 5, peratusan tertinggi yang dicatatkan dalam item konstruk ini adalah item B6 (Saya akan menilai kebaikan dan kelemahan setiap pilihan) dengan 93.7\% (300 orang). Ia diikuti dengan item B1 (Saya teliti apabila membuat keputusan) sebanyak 93.4\% (299 orang). Meskipun, tahap kemahiran membuat keputusan pelajar lelaki dan perempuan pra-universiti berada pada tahap sederhana, namun mereka akan menilai setiap pilihan dan meneliti terlebih dahulu sebelum membuat sebarang keputusan.

Jadual 5: Kemahiran Membuat Keputusan

\begin{tabular}{clcccccccc}
\hline Item & \multicolumn{1}{c}{ Penyataan } & STS & TS & \multicolumn{1}{c}{ S } & \multicolumn{3}{c}{ SS } \\
& No. & \% & No. & \% & No. & \% & No. & \% \\
\hline B1 & $\begin{array}{l}\text { Saya teliti apabila membuat sesuatu } \\
\text { keputusan. }\end{array}$ & 1 & 0.3 & 20 & 6.3 & 200 & 62.5 & 99 & 30.9 \\
B2 & $\begin{array}{l}\text { Saya membuat keputusan dengan } \\
\text { rasional (tidak mengikut emosi). }\end{array}$ & 4 & 1.3 & 36 & 11.3 & 218 & 68.1 & 62 & 19.4 \\
B3 & $\begin{array}{l}\text { Saya membuat keputusan setelah } \\
\text { Saya }\end{array}$ & 2 & 0.6 & 29 & 9.1 & 208 & 65.0 & 81 & 25.3 \\
\hline
\end{tabular}



DOI: https://doi.org/10.47405/mjssh.v7i1.1243

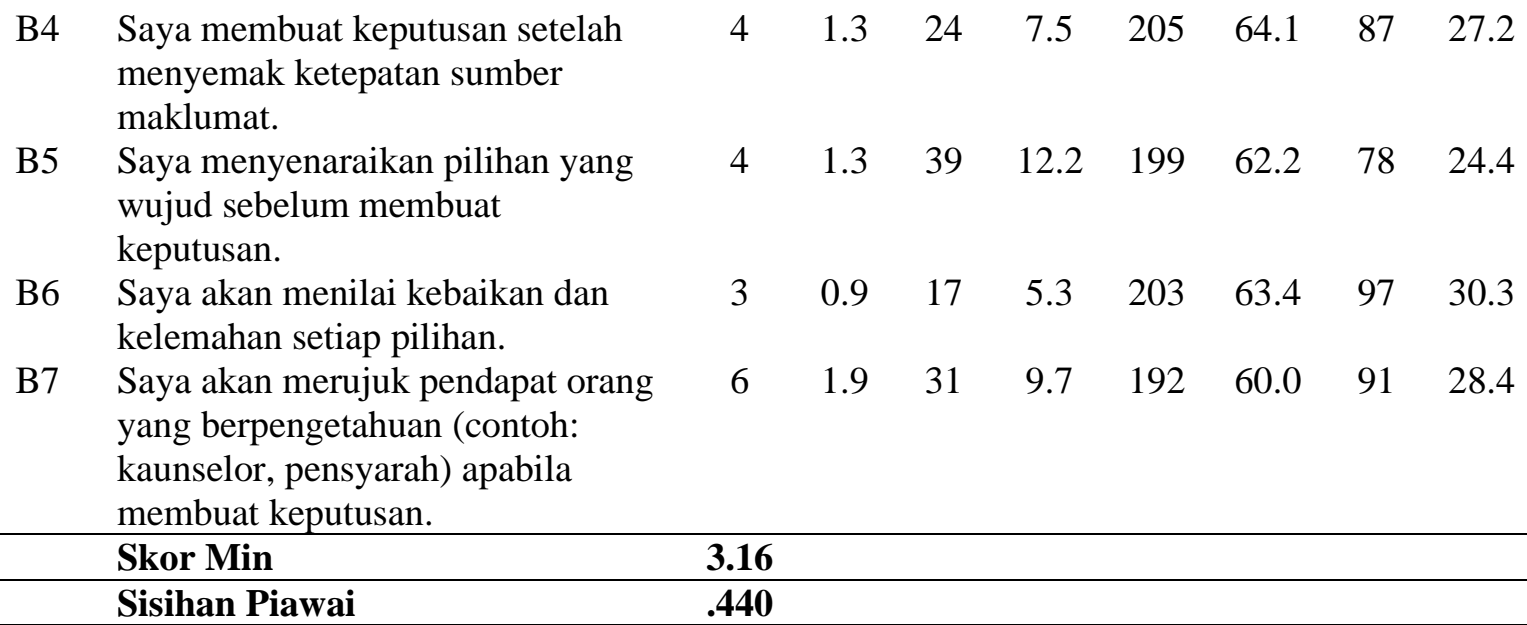

Keberanian mengambil risiko pelajar pra-universiti juga berada pada tahap sederhana secara keseluruhannya dengan merekodkan nilai min 3.15 dan sisihan piawainya .458. Merujuk Jadual 6, item E9 (Saya bertanggungjawab atas keputusan yang saya ambil) mencatatkan frekuensi yang tertinggi dalam item keberanian mengambil risiko sebanyak $98.1 \%$ dengan 314 orang. Namun, 90 orang (28.2\%) tidak bersetuju dengan item E8 (Saya berani menyuarakan pendapat walaupun mungkin dikecam). Hal ini menunjukkan pelajar sanggup bertanggungjawab atas keputusan yang mereka ambil walaupun tidak berani menyatakan pendapat sekiranya dikecam.

Jadual 6: Keberanian Mengambil Risiko

\begin{tabular}{|c|c|c|c|c|c|c|c|c|c|}
\hline \multirow{2}{*}{ Item } & \multirow{2}{*}{ Penyataan } & \multirow{2}{*}{$\begin{array}{l}\text { STS } \\
\text { No. }\end{array}$} & \multicolumn{3}{|c|}{ TS } & \multirow{2}{*}{$\begin{array}{c}\text { S } \\
\text { No. }\end{array}$} & \multicolumn{3}{|c|}{ SS } \\
\hline & & & $\%$ & No. & $\%$ & & $\%$ & No. & $\%$ \\
\hline E1 & $\begin{array}{l}\text { Pengajian di pra-universiti yang } \\
\text { mencabar tidak mematahkan } \\
\text { keazaman saya untuk cemerlang. }\end{array}$ & 7 & 2.2 & 34 & 10.6 & 188 & 58.8 & 91 & 28.4 \\
\hline E2 & $\begin{array}{l}\text { Saya berusaha bersungguh- } \\
\text { sungguh di pra-universiti.. }\end{array}$ & 1 & 0.3 & 19 & 5.9 & 195 & 60.9 & 105 & 32.8 \\
\hline E3 & $\begin{array}{l}\text { Saya memilih pra-universiti kerana } \\
\text { banyak manfaat yang akan } \\
\text { diperoleh berbanding kesukaran } \\
\text { yang perlu dihadapi }\end{array}$ & 2 & 0.6 & 22 & 6.9 & 178 & 55.6 & 118 & 36.9 \\
\hline E4 & $\begin{array}{l}\text { Saya berfikiran positif walaupun } \\
\text { orang lain mengatakan belajar di } \\
\text { pra-universiti susah. }\end{array}$ & 2 & 0.6 & 19 & 5.9 & 155 & 48.4 & 144 & 45.0 \\
\hline E5 & $\begin{array}{l}\text { Saya tidak takut menempuhi } \\
\text { cabaran pengajian di pra-universiti. }\end{array}$ & 5 & 1.6 & 49 & 15.3 & 174 & 54.4 & 92 & 28.7 \\
\hline E6 & $\begin{array}{l}\text { Saya segera bangkit daripada } \\
\text { kegagalan. }\end{array}$ & 1 & 0.3 & 41 & 12.8 & 202 & 63.1 & 76 & 23.8 \\
\hline E7 & $\begin{array}{l}\text { Saya suka menyelesaikan tugasan } \\
\text { yang lebih mencabar berbanding } \\
\text { tugasan yang mudah }\end{array}$ & 7 & 2.2 & 83 & 25.9 & 169 & 52.8 & 61 & 19.1 \\
\hline E8 & $\begin{array}{l}\text { Saya berani menyuarakan pendapat } \\
\text { walaupun mungkin dikecam }\end{array}$ & 4 & 1.3 & 86 & 26.9 & 175 & 54.7 & 57 & 17.2 \\
\hline E9 & $\begin{array}{l}\text { Saya bertanggungjawab atas } \\
\text { keputusan yang saya ambil. }\end{array}$ & 0 & 0.0 & 6 & 1.9 & 193 & 60.3 & 121 & 37.8 \\
\hline E10 & $\begin{array}{l}\text { Saya menyediakan plan kedua } \\
\text { seandainya permohonan saya ke } \\
\text { universiti tidak berjaya. }\end{array}$ & 3 & 0.9 & 32 & 10.0 & 179 & 55.9 & 106 & 33.1 \\
\hline E11 & $\begin{array}{l}\text { Saya segera menyelesaikan } \\
\text { tugasan walaupun sukar. }\end{array}$ & 3 & 0.9 & 46 & 14.4 & 196 & 61.3 & 75 & 23.4 \\
\hline
\end{tabular}


DOI: https://doi.org/10.47405/mjssh.v7i1.1243

\begin{tabular}{ll}
\hline Skor Min & 3.15 \\
\hline Sisihan Piawai & $\mathbf{4 5 8}$ \\
\hline
\end{tabular}

Bagi elemen kemahiran mengesan peluang pula mencatat skor min sebanyak 3.14 dan sisihan piawai .460. Jadual 7 menunjukkan item D4 (Saya mencari maklumat mengenai peluang kerjaya) merekodkan peratusan paling tinggi dalam item elemen ini iaitu 96.6\% (309 orang). Item D2 pula iaitu "Saya mengenal pasti syarat-syarat kelayakan bagi kursus yang saya inginkan" mencatat peratusan kedua tertinggi dengan 95\% iaitu seramai 304 orang. Walaupun analisis menunjukkan tahap kemahiran mengesan peluang pelajar pra-universiti berada pada tahap sederhana, namun mereka tetap mencari peluang sama ada dalam kerjaya atau melanjutkan pengajian di peringkat universiti dengan mencari maklumat kerjaya dan syarat kelayakan kursus pengajian terlebih dahulu.

Jadual 7: Kemahiran Mengesan Peluang

\begin{tabular}{|c|c|c|c|c|c|c|c|c|c|}
\hline \multirow{2}{*}{ Item } & \multirow{2}{*}{ Penyataan } & \multirow{2}{*}{$\begin{array}{l}\text { STS } \\
\text { No. }\end{array}$} & \multicolumn{3}{|c|}{ TS } & \multirow{2}{*}{$\begin{array}{c}\text { S } \\
\text { No. }\end{array}$} & \multicolumn{3}{|c|}{ SS } \\
\hline & & & $\%$ & No. & $\%$ & & $\%$ & No. & $\%$ \\
\hline D1 & $\begin{array}{l}\text { Saya mencari maklumat tentang } \\
\text { program pengajian di universiti. }\end{array}$ & 3 & 0.9 & 27 & 8.4 & 186 & 58.1 & 104 & 32.5 \\
\hline D2 & $\begin{array}{l}\text { Saya mengenal pasti syarat -syarat } \\
\text { kelayakan bagi kursus yang saya } \\
\text { inginkan. }\end{array}$ & 1 & 0.3 & 15 & 4.7 & 183 & 57.2 & 121 & 37.8 \\
\hline D3 & $\begin{array}{l}\text { Saya mengenal pasti peluang bagi } \\
\text { mendapatkan biasiswa di } \\
\text { universiti. }\end{array}$ & 3 & 0.9 & 43 & 13.4 & 193 & 60.3 & 81 & 25.3 \\
\hline D4 & $\begin{array}{l}\text { Saya mencari maklumat mengenai } \\
\text { peluang kerjaya. }\end{array}$ & 1 & 0.3 & 10 & 3.1 & 190 & 59.4 & 119 & 37.2 \\
\hline D5 & $\begin{array}{l}\text { Saya membuat pilihan kursus } \\
\text { ijazah sarjana muda berdasarkan } \\
\text { unjuran permintaan kerjaya. }\end{array}$ & 6 & 1.9 & 40 & 12.5 & 19 & 61.3 & 78 & 24.4 \\
\hline D6 & $\begin{array}{l}\text { Saya memohon program pengajian } \\
\text { yang menawarkan biasiswa. }\end{array}$ & 7 & 2.2 & 68 & 21.3 & 176 & 55.0 & 69 & 21.6 \\
\hline D7 & $\begin{array}{l}\text { Saya mengkaji program pengajian } \\
\text { yang mendapat pengiktirafan }\end{array}$ & 6 & 1.9 & 58 & 18.1 & 182 & 56.9 & 74 & 23.1 \\
\hline D8 & $\begin{array}{l}\text { Malaysian Qualifications Agency. } \\
\text { Saya merujuk pensyarah setelah } \\
\text { melakukan ulang kaji topik yang } \\
\text { tidak saya faham. }\end{array}$ & 4 & 1.3 & 34 & 10.6 & 198 & 61.9 & 84 & 26.3 \\
\hline D9 & $\begin{array}{l}\text { Saya mencontohi gaya belajar } \\
\text { rakan yang lebih cemerlang. }\end{array}$ & 9 & 2.8 & 44 & 13.8 & 167 & 52.2 & 100 & 31.3 \\
\hline & Skor Min & 3.14 & & & & & & & \\
\hline & Sisihan Piawai & .460 & & & & & & & \\
\hline
\end{tabular}

Elemen kreativiti dan inovasi pelajar pra-universiti juga berada pada tahap sederhana dengan skor min 3.13 dan sisihan piawainya .447. Berdasarkan Jadual 8, item F9 (Saya berkolaborasi dengan rakan yang mempunyai kemahiran berbeza dalam menjayakan sesuatu projek) menunjukkan peratusan tertinggi iaitu $94.7 \%$ bersamaan dengan 303 orang pelajar. Selain item F9, item F4 (Saya menggunakan pelbagai kaedah dalam menyelesaikan masalah) juga mencatatkan peratusan yang tinggi iaitu $93.1 \%$ (298 orang).

Jadual 8: Kreativiti Dan Inovasi

\begin{tabular}{|c|c|c|c|c|c|c|c|c|c|}
\hline \multirow{2}{*}{ Item } & \multirow{2}{*}{ Penyataan } & \multirow{2}{*}{$\begin{array}{l}\text { STS } \\
\text { No. }\end{array}$} & \multicolumn{3}{|c|}{ TS } & \multirow{2}{*}{$\begin{array}{c}\text { S } \\
\text { No. }\end{array}$} & \multicolumn{3}{|c|}{ SS } \\
\hline & & & $\%$ & No. & $\%$ & & $\%$ & No. & $\%$ \\
\hline $\mathrm{F} 1$ & $\begin{array}{l}\text { Saya dapat menghasilkan idea } \\
\text { alternatif yang lebih kreatif untuk } \\
\text { menyelesaikan masalah. }\end{array}$ & 5 & 1.6 & 54 & 16.9 & 191 & 59.7 & 70 & 21.9 \\
\hline F2 & Saya suka menghasilkan idea & 1 & 0.3 & 42 & 13.1 & 201 & 62.8 & 76 & 23.8 \\
\hline
\end{tabular}


baharu.

F3 Saya merancang penghasilan produk dengan sistematik untuk mendapat pengiktirafan.

F4 Saya menggunakan pelbagai kaedah dalam menyelesaikan masalah.

F5 Saya selalu berfikir untuk mengubah suai idea sedia ada.

F6 Saya menggabungkan pelbagai kemahiran dalam menyelesaikan tugasan.

F7 Saya dapat menghasilkan idea bermanfaat untuk kehidupan.

F8 Saya mementingkan keaslian dalam hasil kerja.

F9 Saya berkolaborasi dengan rakan yang mempunyai kemahiran berbeza dalam menjayakan sesuatu projek.

F10 Saya dapat menghasilkan idea untuk kejayaan bersama.

F11 Cadangan yang saya kongsi biasanya memberi manfaat kepada orang lain.

\begin{tabular}{ll} 
Skor Min & 3.13 \\
\hline Sisihan Piawai & .447
\end{tabular}

Akhir sekali, elemen kemahiran menyelesaikan masalah mencatat skor min yang terendah dalam minda usahawan iatu 3.12 beserta sisihan piawai .424. Terdapat enam item digunakan bagi mengukur elemen kemahiran menyelesaikan masalah dalam kalangan pelajar lelaki dan perempuan pra-universiti. Merujuk Jadual 9, item C2 dilihat merekodkan frekuensi yang tertinggi iaitu 92.8\% (297 orang) di mana pelajar bersetuju dengan penyataan "Saya merancang strategi menyelesaikan masalah". Namun, $15 \%$ atau 48 orang pelajar memilih tidak membuat penilaian semula untuk penambahbaikan diri pada masa akan dating setelah menyelesaikan masalah (Item C5). Hal ini menunjukkan tahap kemahiran menyelesaikan masalah pelajar lelaki dan perempuan pra-universiti berada pada tahap sederhana.

Jadual 9: Kemahiran Menyelesaikan Masalah

\begin{tabular}{|c|c|c|c|c|c|c|c|c|c|}
\hline \multirow{2}{*}{ Item } & \multirow{2}{*}{ Penyataan } & \multirow{2}{*}{$\begin{array}{l}\text { STS } \\
\text { No. }\end{array}$} & \multicolumn{3}{|c|}{ TS } & \multirow{2}{*}{$\begin{array}{c}\text { S } \\
\text { No. }\end{array}$} & \multicolumn{3}{|c|}{ SS } \\
\hline & & & $\%$ & No. & $\%$ & & $\%$ & No. & $\%$ \\
\hline $\mathrm{C} 1$ & $\begin{array}{l}\text { Saya mengenal pasti punca } \\
\text { masalah dengan jelas. }\end{array}$ & 2 & 0.6 & 29 & 9.1 & 218 & 68.1 & 71 & 22.2 \\
\hline $\mathrm{C} 2$ & $\begin{array}{l}\text { Saya merancang strategi } \\
\text { menyelesaikan masalah. }\end{array}$ & 1 & 0.3 & 22 & 6.9 & 218 & 68.1 & 79 & 24.7 \\
\hline $\mathrm{C} 3$ & $\begin{array}{l}\text { Saya mengenal pasti perkara yang } \\
\text { mungkin menjadi halangan dalam } \\
\text { menyelesaikan masalah. }\end{array}$ & 2 & 0.6 & 28 & 8.8 & 214 & 66.9 & 76 & 23.8 \\
\hline $\mathrm{C} 4$ & $\begin{array}{l}\text { Saya bertindak berdasarkan usaha- } \\
\text { usaha yang disenaraikan dalam } \\
\text { pernyataan. }\end{array}$ & 4 & 1.3 & 35 & 10.9 & 218 & 68.1 & 63 & 19.7 \\
\hline C5 & $\begin{array}{l}\text { Setelah masalah selesai, saya } \\
\text { membuat penilaian semula untuk } \\
\text { penambahbaikan diri pada masa } \\
\text { akan datang. }\end{array}$ & 3 & 0.9 & 45 & 14.1 & 200 & 62.5 & 72 & 22.5 \\
\hline C6 & $\begin{array}{l}\text { Saya mengubah gaya belajar untuk } \\
\text { lebih cemerlang. }\end{array}$ & 3 & 0.9 & 22 & 6.9 & 211 & 65.9 & 84 & 26.3 \\
\hline
\end{tabular}


DOI: https://doi.org/10.47405/mjssh.v7i1.1243

\begin{tabular}{ll}
\hline Skor Min & 3.12 \\
\hline Sisihan Piawai & $\mathbf{4 2 4}$ \\
\hline
\end{tabular}

\section{Tahap Perbezaan Minda Usahawan Pelajar Lelaki dan Perempuan Pra-Universiti}

Hasil ujian-t tidak bersandar yang dilaksanakan mendapati tidak terdapat perbezaan yang signifikan terhadap tahap minda usahawan antara pelajar lelaki dan perempuan pra-universiti bagi elemen kemahiran membuat keputusan dengan nilai $[\mathrm{t}=-1.393, \mathrm{p}=0.165], \mathrm{p}>0.05$; kemahiran menyelesaikan masalah dengan nilai $[\mathrm{t}=-0.688, \mathrm{p}=0.492], \mathrm{p}>0.05$; keberanian mengambil risiko dengan nilai $[\mathrm{t}=-0.402, \mathrm{p}=0.688], \mathrm{p}>0.05$; kreativiti dan inovasi dengan nilai $[\mathrm{t}=0.329, \mathrm{p}=0.743$, $\mathrm{p}>0.05$; dan kemahiran bekerja dalam pasukan dengan nilai $[\mathrm{t}=-1.142, \mathrm{p}=0.254], \mathrm{p}>0.05$. Namun, terdapat perbezaan yang signifikan tahap minda usahawan pelajar lelaki dan perempuan pra-universiti bagi elemen kemahiran mengesan peluang dengan nilai $[t=-2.588, p=0.010], p<0.05$.

Secara keseluruhannya, tidak terdapat perbezaan signifikan tahap minda usahawan antara pelajar lelaki dan perempuan pra-universiti dengan nilai $[\mathrm{t}=-1.217, \mathrm{p}=0.225], \mathrm{p}>0.05$. Berdasarkan kepada analisis, skor min pelajar perempuan melebihi pelajar lelaki untuk kesemua elemen minda usahawan kecuali kreativiti dan inovasi. Pelajar lelaki dilihat lebih menguasai elemen kreativiti dan inovasi berbanding pelajar perempuan dengan nilai skor min iaitu 3.14.

Jadual 10: Perbezaan Tahap Minda Usahawan Berdasarkan Jantina

\begin{tabular}{|c|c|c|c|c|c|c|}
\hline & Jantina & n & Min & SP & Nilai $t$ & Sig.P \\
\hline \multirow{4}{*}{$\begin{array}{l}\text { Kemahiran membuat } \\
\text { keputusan } \\
\text { Kemahiran menyelesaikan } \\
\text { masalah }\end{array}$} & Lelaki & 128 & 3.12 & .399 & \multirow[t]{2}{*}{-1.393} & \multirow[t]{2}{*}{.165} \\
\hline & Perempuan & 192 & 3.18 & .464 & & \\
\hline & Lelaki & 128 & 3.10 & .357 & \multirow[t]{2}{*}{-.688} & \multirow[t]{2}{*}{.492} \\
\hline & Perempuan & 192 & 3.13 & .46455 & & \\
\hline \multirow{2}{*}{$\begin{array}{l}\text { Kemahiran mengesan } \\
\text { peluang }\end{array}$} & Lelaki & 128 & 3.07 & .39965 & \multirow[t]{2}{*}{-2.588} & \multirow[t]{2}{*}{.010} \\
\hline & Perempuan & 192 & 3.19 & .48983 & & \\
\hline \multirow{2}{*}{$\begin{array}{l}\text { Keberanian mengambil } \\
\text { risiko }\end{array}$} & Lelaki & 128 & 3.14 & .43064 & \multirow[t]{2}{*}{-.402} & \multirow[t]{2}{*}{.688} \\
\hline & Perempuan & 192 & 3.16 & .47670 & & \\
\hline \multirow[t]{2}{*}{ Kreativiti dan inovasi } & Lelaki & 128 & 3.14 & .42482 & \multirow[t]{2}{*}{.329} & \multirow[t]{2}{*}{.743} \\
\hline & Perempuan & 192 & 3.13 & .46278 & & \\
\hline \multirow{2}{*}{$\begin{array}{l}\text { Kemahiran bekerja dalam } \\
\text { pasukan }\end{array}$} & Lelaki & 128 & 3.20 & .42967 & \multirow[t]{2}{*}{-1.142} & \multirow[t]{2}{*}{.254} \\
\hline & Perempuan & 192 & 3.26 & .47538 & & \\
\hline \multirow{2}{*}{ Tahap minda usahawan } & Lelaki & 128 & 3.13 & .31901 & \multirow[t]{2}{*}{-1.217} & \multirow[t]{2}{*}{.225} \\
\hline & Perempuan & 192 & 3.18 & .39497 & & \\
\hline
\end{tabular}

\section{Perbincangan Kajian}

Berdasarkan dapatan kajian, secara keseluruhan tahap minda usahawan pelajar lelaki dan perempuan pra-universiti berada pada tahap sederhana dengan skor min 3.16. Hal ini disebabkan pelajar telah didedahkan elemen-elemen minda usahawan sejak dari peringkat awal lagi yang diterapkan dalam mata pelajaran bagi mencapai matlamat pendidikan negara iaitu melahirkan pelajar yang kompetitif dan seimbang dari segi intelek, emosi, jasmani dan rohani. Dapatan kajian ini selari dengan dapatan kajian Affzalina dan Nor Aishah (2017) yang mendapati tahap pemikiran atau minda keusahawanan berada pada tahap yang sederhana. Namun, dapatan kajian ini berbeza dengan dapatan dalam kajian Muhammad Syafiq et al. (2021) yang dilakukan terhadap anak-anak golongan asnaf di Selangor yang mempunyai tahap minda keusahawanan yang tinggi. Hal ini kerana anak-anak golongan asnaf mempunyai efikasi yang tinggi untuk menjadi seorang usahawan. Seterusnya, elemen kemahiran bekerja dalam pasukan merupakan elemen minda usahawan yang mempunyai skor min yang tertinggi iaitu 3.24 berbanding dengan lima elemen yang lain dan berada pada tahap yang sederhana. 
Dapatan kajian daripada ujian-t tidak bersandar yang dijalankan menunjukkan tiada perbezaan signifikan tahap minda usahawan pelajar lelaki dan perempuan pra-universiti. Dapatan kajian ini tidak selari dengan dapatan kajian Azmi et al. (2012) yang mendapati terdapat perbezaan yang signifikan antara pelajar lelaki dan perempuan terhadap potensi keusahawanan. Hal ini kerana pelajar lelaki lebih memahami dan menyedari kepentingan bidang keusahawanan serta memilihnya sebagai kerjaya pada masa depan dan ia berbeza dengan pelajar perempuan yang majoritinya tidak berminat untuk berkecimpung dalam bidang keusahawanan walaupun memahami dan menyedari kepentingannya. Namun, kajian Azmi et al. (2012) mendapati tidak terdapat perbezaan yang signifikan pelajar lelaki dan perempuan terhadap ciri-ciri keusahawanan. Ini menunjukkan pelajar lelaki dan perempuan mempunyai ciri-ciri keusahawanan yang sama.

\section{Kesimpulan}

Tahap minda usahawan pelajar lelaki dan perempuan pra-universiti masih berada pada tahap yang sederhana. Walaupun elemen-elemen minda usahawan telah diterapkan dari peringkat sekolah lagi, namun pelajar tidak menguasainya dengan baik. Kajian juga mendapati tiada perbezaan tahap minda usahawan antara pelajar lelaki dan perempuan pra-universiti. Ini menunjukkan pelajar pra-universiti mempunyai elemen-elemen minda usahawan yang sama. Maka, jelaslah tahap minda usahawan pelajar lelaki dan perempuan pra-universiti adalah sederhana dan tidak mempunyai perbezaan antara mereka.

Implikasi dalam kajian ini mencadangkan agar pelajar didedahkan dengan lebih luas terhadap pengetahuan dan pengalaman keusahawanan. Hal ini kerana pengetahuan dan pengalaman keusahawanan dapat meningkatkan tahap minda usahawan pelajar seterusnya mendorong kepada tingkah laku keusahawanan.

Kajian lanjutan yang boleh dilaksanakan adalah mengkaji tahap minda usahawan dalam kalangan pelajar sekolah menengah. Kajian yang lebih lanjut dapat membantu pihak sekolah khususnya untuk membentuk elemen-elemen minda usahawan pelajar sekolah dengan lebih baik.

\section{Rujukan}

Abdullah, M. S., \& Rahman, S. (2017). Kemahiran Membuat Keputusan dalam Kalangan Pelajar Sekolah Menengah. Seminar Serantau, 124-127.

Abdullah, N. L., Senik, Z. C., \& Sidek, F. (2019). Mengenal Pasti Peluang. Dlm. Othman, N., Hassan, R., \& Zaki, W. M. D. W. (Eds.), Pendidikan Asas Keusahawanan (pp. 55-74). Bangi: Universiti Kebangsaan Malaysia.

Abdullah, Z., \& Rahman, S. (2015). Kemahiran Meta-Tingkah Laku dan Kemahiran Membuat Keputusan Pelajar Bermasalah Disiplin dan Tidak Bermasalah Disiplin. Jurnal Pendidikan Malaysia, 40(2), 175-183.

Ahmad, R., Hassan, H., \& Ariffin, A. A. W. (2016). Pembudayaan Kreativiti dan Inovasi Dalam Kalangan Pelajar Institut Pengajian Tinggi: Kajian Ke Atas Pelajar Universiti Malaysia Perlis.

Akindele, D. O. (2012). Enhancing Teamwork and Communication Skills Among First Year Students at the University of Botswana. TESOL Journal, 6, 2-15.

Alagappan, V., \& Othman, N. (2016). Isu-Isu Kesediaan Guru Dalam Membudayakan Minda Keusahawanan Pelajar. Seminar Antarabangsa Pendidikan Global IV, 1070-1076.

Amin, H. M., Jaafar, J., Hood, Z., Saad, S., \& Amin, H. M. (2013). Kemahiran Insaniah Pelajar Prasiswazah: Analisi Perbezaan Jantina. Jurnal Teknologi, 61(1), 19-25.

Arfiana, A., \& Wijaya, A. (2018). Problem Solving Skills of Students of Senior High Schools and Islamic High Schools in Tegal Regency in Solving The Problem of PISA Based on Polya's Stage. Jurnal Riset Pendidikan Matematika, 5(2), 211-222.

Arifin, M. A., \& Aishah, R. S. (2019). Hubungan Antara Ciri-ciri Keusahawanan Dengan Aspirasi Keusahawanan Pelajar Diploma Vokasional Malaysia (DVM) di Kolej Vokasional Ranaco Marin. Journal of Global Business and Social Entrepreneurship, 5(15), 46-60. 
Bosman, L. \& Fernhaber, S. (2018). Teaching the Entrepreneurial Mindset to Engineers. Springer International Publishing AG.

Dorin, A. D. A., \& Rahman, M. J. A. (2019). Falsafah Pendidikan Dari Pelbagai Perspektif. Dlm. Rahman, M. J. A., \& Zain, N. M. (Eds.), Guru dan Isu Pendidikan, (pp. 11-16). Bangi: Universiti Kebangsaan Malaysia.

Farida, J. (2019). Pengaruh Kecenderungan Mengambil Risiko dan Dukungan Lingkungan Terhadap Intensi Berwirausaha Melalui Motivasi Berwirausaha Pada Mahasiswa Pendidikan Ekonomi Fakultas Ekonomi UNNES. [Tesis Sarjana]. Universitas Negeri Semarang.

Global Partnership for Education. (2020). Access to Education.

Greenbank, P. (2010). Developing Decision-making Skills in Students: An Active Learning Approach. Edge Hill University.

Hamid, M. F. A., Ling, M. A. W., Jaafar, S. B., \& Hassan, H. (2014). Keberkesanan Kerja Berpasukan Terhadap Komunikasi Pelajar Latihan Industri. Conference Proceeding 24-25 June 2014, 255 260.

Hassan, A., \& Buang, N. A. (2017). Perbandingan Tahap Sikap, Pemikiran dan Tingkah Laku Keusahawanan dengan Tahap Perancangan Berniaga Mahasiswa Jurusan Sains. Journal of Global Business and Social Entrepreneurship, Vol. 1(1), 86-99.

Hassan, N. A., \& Hamid, M. A. A. (2019). Penyelesaian Masalah Menerusi Pembelajaran Informal Dalam Kalangan Usahawan: Suatu Pandangan Awal. International Social Science Conference $6^{\text {th }}$.

Indeks Jurang Gender Global. (2021). Indeks Jurang Gender Global Bagi Negara ASEAN dan NegaraNegara Terpilih Mengikut Indeks Negara.

Ismail, M. H. (2012). Kajian Mengenai Kebolehpasaran Siswazah di Malaysia: Tinjauan dari Perspektif Majikan. Prosiding PERKEM VII, 2, 906-913.

Ismail, M., \& Shaharuddin, W. Y. W. (2014). Pembangunan Komuniti Berorientasikan Keusahawanan Sosial: Kajian Kes Organisasi Bukan Kerajaan di Malaysia. International Conference on Social Entrepreneurship (ICSE).7-9 Nov 2014.

Ismail, R., Yussof, I., \& Lai, W. S. (2011). Employers' Perceptions On Graduates in Malaysia Services Sector. International Business Management, 5(3), 184-193.

Kuang, C. Y., Szu, C. F., \& Kuen, Y. L. (2014). Enhancing Students' Problem Solving Skills Through Context Based Learning. International Journal of Science and Mathematics Education, 13(6).

Laporan Daya Saing Global. (2020). Report in Doing Business 2020.

Latif, A. A. A., Jusoh, M. A., Yahya, M. A., Jusoh, O., \& Hamidon, S. (2011). Asas Keusahawanan dan Pengurusan Perniagaan Kecil dan Sederhana. Kota Bharu: Universiti Malaysia Kelantan.

Makhbul, Z. M., Yussof, I., \&Awang, A. H. (2015). Antara Realiti dan Harapan - Kajian Empirikal Persepsi Majikan terhadap Prestasi Graduan Tempatan. GEOGRAFIA: Malaysian Journal of Society and Space, 11(10), 27-36.

Mat, N., Noordin, M. S., Abdullah, N. A., Muslim, N., \& Alias, J. (2017). Pembentukan Kemahiran Insaniah Pelajar Melalui Badan Beruniform di Universiti Kebangsaan Malaysia. Jurnal Personalia Pelajar, 20, 33-46.

Mohamad, A., Hashim, N., Ishak, A. K., \& Abdullah, S. (2020). Pemikiran Keusahawanan Pelajar Institut Pengajian Tinggi Awam Malaysia dan Hubungkaitnya Dengan Bidang Pengajian Pelajar. International Journal of Education, Psychology and Counselling, Vol. 5(35), 321-331.

Munoz, C. C. A., Mosey, S., \& Binks, M. (2011). Developing Opportunity-Identification Capabilities in The Classroom: Visual Evidence for Changing Mental Frames. Academy of Management Learning \& Education, 2, 277-295.

Nab, J. (2015). Teaching Science Students To Identify Entrepreneurial Opportunity.

Naumann, C. (2017). Entrepreneurial Mindset: A Synthetic Literature Review. Entrepreneurial Business and Economic Review, 5(3), 149-172.

Nasir, M., \& Yunus, H. M. (2017). Peranan Guru Tingkatan Enam Dalam Membentuk Pelajar Terarah Kendiri dan Meningkatkan Kemahiran Abad Ke-21. Jurnal Kurikulum \&Pengajaran Asia Pasifik, 5(1),1-6.

Ngadiman, S. H., \& Jamaludin, M. F. (2018). Hubungan Di Antara Kemahiran Kerja Berpasukan dan Kemahiran Komunikasi Dalam Kalangan Pelajar Semester Akhir Politeknik. International Journal of Education, Psychology and Counseling, 3(19), 01-18.

Poh, B. T., \& Abdullah, M. N. L. Y. (2008). Kesan Faktor Jantina, Etnik dan Gaya Kognitif Ke Atas Pencapaian Pengajian Am. Jurnal Pendidik dan Pendidikan, 23, 123-140. 
DOI: https://doi.org/10.47405/mjssh.v7i1.1243

Sarju, H., Hamzah, R., \& Udin, A. (2010). Pendidikan: matlamat dan fungsinya. Edupress 2010. http://eprints.utm.my/id/eprint/14919/1/Pendidikan_-_eprint4.pdf.

Suhaimi, S., Abdullah, S. A. J., Arshad, R., Yeon, A. L., Azhar, A., \& Ayub, Z. A. (2016). Penyertaan Belia Dalam Membuat Keputusan Melahirkan Kemahiran Kepimpinan. Proceeding of The International Conference on Government \& Public Affairs 2016, 1-7.

Sulaiman, M., Mat, Z., Hussain, F. C., Sulaiman@Mohamad, A., Nizah, M. A. M., \& Latiff, L. A. (2017). The Impact of Teamwork Skills on Students in Malaysian Public Universities. The Social Science, 12(9), 1682-1686.

Taylor, S. P. (2018). Creativity in Innovation. Tidak Diterbitkan.

Wasdani, K. P. (2015). Opportunity Recognition (OR) skills of entrepreneurs and Its Association with Their Paths to Business Ownership and Types of Innovation: An Empirical Investigation of SME Firms. Kindai Management Review, 3.

World Economic Forum. (2018). The Global Competitiveness Report 2018.

Yahaya, A. (2010). Bab 8: Penyelesaian Masalah. Psikologi Pendidikan. Skudai: Universiti Teknologi Malaysia.

Yusoff, H. M., \& Azman, N. (2018). Pencapaian Akademik Murid Lelaki dan Perempuan: Peranan Sokongan Pembelajaran dan Keterlibatan Murid. Malaysian Journal of Learning and Instruction, 15(2), 257-287.

Zakaria, M. S., Sahid, S., \& Othman, N. (2021). Tahap Budaya Keusahawanan dan Kepimpinan Keusahawanan serta Hubungannya dengan Minda Keusahawanan Anak-anak Golongan Asnaf. Malaysian Journal of Social Sciences and Humanities (MJSSH), 6(3), 104-119.

Zulkifli, N., Hamzah, M. I., \& Razak, K. A. (2020). Faktor Pendorong Kreativiti Dalam Kalangan Pelajar Politeknik. Asian People Journal, 3(2), 77-85. 